\title{
RESISTÊNCIA DE GENÓTIPOS DE FEIJOEIROA Zabrotes subfasciatus (BOHEMANN, 1833) (COLEOPTERA: BRUCHIDAE)
}

\author{
Resistance of genotypes to Zabrotes subfasciatus (Bohemann, 1833) (Coleoptera: Bruchidae)
}

\author{
Edson Luiz Lopes Baldin¹, Jaqueline Magalhães Pereira²
}

\begin{abstract}
RESUMO
Durante o armazenamento de grãos de feijão (Phaseolus vulgaris L.), o rendimento pode ser reduzido devido às infestações de carunchos como os da espécie Zabrotes subfasciatus (Bohemann, 1833) (Coleoptera: Bruchidae). O ataque desse inseto afeta diretamente a qualidade dos grãos, além de facilitar a entrada de patógenos, tornando-os inviáveis para o consumo e/o comércio. Com a finalidade de buscar uma estratégia alternativa para o controle deste caruncho, avaliou-se a possível resistência de linhagens quase isogênicas contendo arcelina, linhagens selvagens contendo arcelina e cultivares comerciais de feijoeiro, em laboratório $\left(\mathrm{T}=25 \pm 2^{\circ} \mathrm{C}, \mathrm{U} \cdot \mathrm{R} .=70 \pm 10 \%\right.$ e fotoperíodo $=12 \mathrm{~h}$ ). Foram utilizados frascos contendo $10 \mathrm{~g}$ de grãos dos genótipos, os quais foram infestados por uma semana com sete casais do caruncho. Vinte e um dias após a infestação, os grãos foram avaliados contando-se o número de ovos viáveis. A partir de 25 dias da infestação, os grãos foram observados diariamente avaliando-se o número e o peso dos insetos emergidos, a viabilidade larval, o ciclo biológico (ovo-adulto) e o peso de grãos consumidos. Empregou-se um delineamento inteiramente casualizado, com oito repetições. Os genótipos Arc.2, Arc.3, Arc.4, Arc.3S e Ipa 6 expressaram baixos níveis de não-preferência para oviposição e foram classificados como deterrentes. Os genótipos Arc.1S e Arc.1 expressaram elevados níveis de antibiose; Arc.2, Arc.3 e Arc.4 apresentam o mesmo mecanismo, porém, em níveis inferiores.
\end{abstract}

Termos para indexação: Resistência de plantas a insetos, feijão armazenado, caruncho, antixenose, antibiose.

\begin{abstract}
During the storage of bean grains (Phaseolus vulgaris L.), production may be reduced due to weevils attack such as the species Zabrotes subfasciatus (Bohemann, 1833) (Coleoptera: Bruchidae). This insect attack affects directly the quality of grain and facilitates the entry of pathogens, making them impractical for consumption and trade. In order to find an alternative strategy to control of this pest, we assessed the possible resistance of near isogenic lines containing arcelin, wild lines containing arcelin and cultivars, in laboratory $\left(T=25 \pm 2^{\circ} \mathrm{C}, \mathrm{R} . \mathrm{H} .=70 \pm 10 \%\right.$ and photoperiod $\left.=12 \mathrm{~h}\right)$. The assays were conducted in vials containing $10 \mathrm{~g}$ of bean grains per genotype, releasing seven pairs of the insect and maintaining the infestation during one week. Twenty-one days after the releasing, the grains were evaluated counting the viable eggs. Twenty-five days after the infestation, the evalutions were daily initiated, observing the number of adults emerged, larvae viability, development period (egg to adult) and weight of grains consumed. The assays were performed in a completely randomized design with eight replicates. The genotypes Arc.2, Arc.3, Arc.4, Arc.3S and Ipa 6 showed low levels of oviposition non-preference, being classified as deterrents. The genotypes Arc.1S and Arc.1 expressed high levels of antibiosis; Arc.2, Arc.3 and Arc.4 showed the same mechanism, however in lower levels.
\end{abstract}

Index terms: Host plant resistance, stored bean grains, bean weevil, antixenosis, antibiosis.

(Recebido em 4 de fevereiro de 2010 e aprovado em 9 de agosto de 2010)

\section{INTRODUÇÃO}

O feijão é uma das mais importantes fontes de proteína para o povo brasileiro e também para grande parte da América Latina e México, além de apresentar elevado conteúdo energético quando comparado a outros gêneros alimentícios (Gusmàn Maldonado et al., 1996). O Brasil é o maior produtor e consumidor mundial de feijão, ocupando uma área de aproximadamente 4,2 milhões de hectares, com uma produção de 3,5 milhões de toneladas (Conab, 2009).
Além das pragas que ocasionam redução na produtividade, no campo, durante o armazenamento dos grãos ocorrem muitas perdas associadas ao ataque de insetos, dentre eles o caruncho Zabrotes subfasciatus (Bohemann, 1833) (Coleoptera: Bruchidae) (Schoonhoven \& Cardona, 1982; Cardona et al., 1989). Os danos de $Z$. subfasciatus são decorrentes da penetração e alimentação das larvas no interior dos grãos, os quais provocam perda de peso e redução no valor nutritivo. Além disso, reduzem a taxa de germinação e desvalorizam o produto comercial pela presença de insetos mortos, fezes e orifícios de

\footnotetext{
${ }^{1}$ Universidade Estadual Paulista Júlio de Mesquita Filho/UNESP - Departamento de Produção Vegetal - José Barbosa de Barros - 1780 - Cx. P. 237 18610-307 - Botucatu, SP - elbaldin@fca.unesp.br

2Universidade Estadual Paulista Júlio de Mesquita Filho/UNESP - Departamento de Produção Vegetal - Botucatu, SP
} 
emergência dos adultos (Minney et al., 1990; Yokoyama, 1996).

O controle deste caruncho tem sido realizado pelo uso de inseticidas fumigantes como fosfeto de alumínio, fosfina de hidrogênio e tetracloreto de carbono (Hill, 2002). Contudo, embora o controle químico seja eficiente, essa prática é de difícil acesso para os pequenos produtores, devido ao elevado custo e possíveis riscos de toxicidade, inerentes ao uso de produtos químicos (Pereira et al., 1995).

$\mathrm{O}$ estudo de resistência de plantas como alternativa de controle ao ataque de bruquídeos vem sendo realizado no Brasil (Pereira et al., 1995; Oriani et al., 1996, Mazzonetto \& Boiça Júnior, 1999; Baldin et al., 2004) e em outros países (Schoonhoven et al., 1982, Kornegay et al., 1993). Como vantagens dessa técnica, podem-se citar a diminuição do uso de inseticidas, o baixo custo, a facilidade de utilização e principalmente a compatibilidade com outros métodos de controle (Lara, 1991)

Casos de resistência varietal a Z. subfasciatus têm sido relatados em diversas variedades de feijão, sendo o mecanismo de resistência do tipo antibiose o mais frequente (Schoonhoven et al., 1983; Cardona et al., 1989, 1992; Kornegay et al., 1993; Oriani et al., 1996). As bases bioquímicas de resistência a Z . subfasciatus estão geralmente associadas à presença de proteínas denominadas arcelinas. Esses compostos, encontrados em materiais resistentes, impedem a proteólise de enzimas produzidas pelas larvas dos insetos, impedindo e indisponibilizando aminoácidos essenciais (Posso et al., 1992; Pereira et al., 1995). Alguns estudos mostraram que a proteína arcelina, presente em linhagens selvagens resistentes e ausente em linhagens suscetíveis e em genótipos cultivados, está associada à resistência aos bruquídeos (Lara 1997, 1998; Barbosa et al., 2000a, 2000b, Baldin et al., 2007).

Neste sentido, realizou-se o presente trabalho, utilizando linhagens quase isogênicas contendo arcelina, linhagens selvagens contendo arcelina e cultivares comerciais de feijoeiro (Phaseolus vulgaris L.), visando identificar possíveis mecanismos de resistência ao caruncho Z. subfasciatus, em condições de laboratório.

\section{MATERIAL E MÉTODOS}

O trabalho foi conduzido no Laboratório de Resistência de Plantas a Insetos e Plantas Inseticidas (LARESPI) da FCA/UNESP, Botucatu, SP, durante o ano de 2009. Para a realização dos ensaios, foi mantida uma criação estoque de $Z$. subfasciatus no interior de uma câmara climática (B.O.D.) $\left(\mathrm{T}=25^{\circ} \mathrm{C} \pm 2{ }^{\circ} \mathrm{C}\right.$; U.R. $=70 \% \pm 5 \%$ e fotoperíodo $=12 \mathrm{~h}$ ).
$\mathrm{Na}$ criação foram utilizados frascos de vidro transparentes $(1 \mathrm{~L})$, fechados na parte superior com uma tela de nylon ( 35 mesh), permitindo a aeração interna. Cada frasco recebeu $0,3 \mathrm{~kg}$ de grãos de feijão Bolinha recémcolhidos, sendo infestados com aproximadamente 300 adultos de Z. subfasciatus.

Foram utilizados grãos recém-colhidos de linhagens quase isogênicas, contendo arcelina dos tipos 1, 2, 3 e 4 (Arc.1, Arc.2, Arc.3, Arc.4), duas linhagens selvagens, contendo arcelina dos tipos 1 e 3 (Arc.1S, Arc.3S), e quatro genótipos comerciais (Carioca Pitoco, Ipa 6, Porrilo 70, Onix).

Para início do ensaio sem chance de escolha, recipientes plásticos transparentes $(5,0 \times 3,5 \mathrm{~cm})$ receberam $10 \mathrm{~g}$ de grãos dos genótipos juntamente com sete casais adultos de Z subfasciatus com 48 horas de idade. Posteriormente, os recipientes foram fechados e acondicionados em B.O.D., sob as mesmas condições ambientais já descritas. A infestação foi mantida por um período de sete dias, quando os insetos foram retirados. Adotou-se um delineamento inteiramente casualizado, com oito repetições.

Após vinte e um dias da infestação, foram contabilizados o número de ovos e a percentagem de ovos viáveis. $\mathrm{O}$ índice de preferência para oviposição (Fenemore, 1980) foi determinado pela fórmula: $I P O=[(T-P / T+P)] x$ 100 , sendo $\mathrm{T}$ o número de ovos contados no tratamento avaliado e $\mathrm{P}$ o número de ovos contados no genótipo suscetível padrão (Carioca Pitoco). O índice varia de 100, para muito estimulante, zero para neutro, até -100 para total deterrência. A classificação foi feita a partir da comparação das médias de ovos dos tratamentos com a média do tratamento padrão, levando-se em consideração o erro padrão da média do ensaio para a diferenciação dos mesmos.

Com 25 dias da infestação inicial, as parcelas passaram a ser avaliadas diariamente a fim de se determinarem a viabilidade larval, o número e peso seco de adultos emergidos, o período de desenvolvimento (ovo-adulto) e o peso seco de grãos consumidos por Z. subfasciatus.

Os adultos recém-emergidos do caruncho foram acondicionados em vidros $(2,2 \times 5,0 \mathrm{~cm})$ e imediatamente conduzidos a um freezer para uma rápida interrupção do ciclo vital, evitando perdas de peso e mantendo-seem perfeito estado de conservação. Ao término da emergência dos adultos, esses vidros foram abertos e colocados em estufa $\left(50^{\circ} \mathrm{C}\right)$ por $48 \mathrm{~h}$ para determinação do peso seco dos insetos. O consumo dos grãos pelas larvas do caruncho foi determinado comparando-se o peso seco das parcelas infestadas com os das testemunhas (não infestadas). 
Os resultados obtidos foram submetidos à análise de variância pelo Teste F, sendo as médias comparadas pelo teste de Tukey ao nível de 5\% de probabilidade, utilizandose o software ESTAT 2.0 (UNESP de Jaboticabal, SP).

\section{RESULTADOS E DISCUSSÃO}

Com relação às médias de oviposição de $\mathrm{Z}$. subfasciatus sobre os grãos dos genótipos de feijoeiro, observa-se que não houve diferença significativa entre os materiais. Também não foram detectadas diferenças quanto à viabilidade dos ovos (Tabela 1).

Comparando-se os genótipos contendo arcelina aos demais, nota-se que não houve redução na oviposição (Tabela 1). Os genótipos contendo arcelina não reduziram a viabilidade dos ovos de Z. subfasciatus em testes sem chance de escolha conforme relatado por Lara, (1997), Wanderley et al. (1997), Mazzoneto \& Vendramim (2002), Ribeiro-Costa et al. (2007).

Contudo, por meio do índice de preferência para oviposição (IPO), foi possível constatar que os genótipos Arc.2, Arc.3, Arc.4, Arc.3S, Ipa 6 foram classificados como deterrentes (Figura 1) em relação aos genótipos carioca Pitoco, suscetível padrão. A deterrência ocasionada pelos genótipos pode estar associada à presença de compostos voláteis que ao serem detectados pelas fêmeas de $Z$. subfasciatus inibem seu comportamento de oviposição, reduzindo significativamente a postura sobre os grãos. Os tratamentos 'Arc.1', 'Arc.1S', 'Porrilo 70' e 'Onix' foram considerados neutros ou semelhantes quanto à oviposição. Em estudo semelhante com A. obtectus, Baldin \& Lara (2008) constataram não-preferência para oviposição nos genótipos Arc.1S, Arc.3S, Arc.2 e Arc.5, com médias de ovos iguais a 70,$5 ; 86,5 ; 80,1$ e 74,3, respectivamente. No presente trabalho, não houve diferença entre os genótipos quanto ao número de ovos; contudo 'Arc.2' $(57,0)$ e 'Arc.3S' $(65,25)$ foram classificados como deterrentes, indicando uma menor preferência também para Z. subfasciatus.

Com relação à viabilidade larval e ao número de insetos emergidos, observa-se que os genótipos Arc.1, Arc.1S e Arc. 2 apresentaram as menores médias, diferindo significativamente dos demais materiais (Tabela 2). Seu menor índice de emergência, respectivamente $11,75 \% ; 12,13 \%$ e $8,75 \%$, pode estar relacionado à ocorrência de antibiose como mecanismo de resistência, geralmente caracterizado pela elevada mortalidade larval (Baldin \& Lara, 2004).

Quanto ao período médio de desenvolvimento de ovo a adulto, observou-se que os genótipos Carioca Pitoco, Porrilo 70, Ipa 6 e Arc.3S, apresentaram médias significativamente menores que os demais materiais, revelando serem mais adequados para o desenvolvimento do inseto e, portanto, suscetíveis (Tabela 2). O prolongamento do período de ovoadulto obtido nos genótipos Arc.1, Arc.2, Arc.3, Arc.4 e Arc.1S indica a ocorrência de não-preferência para alimentação e/ou antibiose. Em trabalho realizado por Baldin \& Lara (2008), os genótipos Arc.1S, Arc.5S e Arc.2 também expressaram elevada resistência do tipo antibiose para o caruncho Acanthoscelides

Tabela 1 - Médias ( \pm EP) de oviposição de Z. subfasciatus obtidos em diferentes genótipos de feijoeiro. $\left(\mathrm{T}=26 \pm 2^{\circ} \mathrm{C}\right.$; $\mathrm{UR}=70 \pm 10 \%$ e fotofase de $12 \mathrm{~h}$ ).

\begin{tabular}{lccc}
\hline Genótipos & Ovos totais $^{1,2}$ & Ovos viáveis $^{1,2}$ & ${\text { Viabilidade }(\%)^{1}}^{1}$ \\
\hline Ônix & $82,75 \pm 10,20 \mathrm{a}$ & $65,25 \pm 8,90 \mathrm{a}$ & $77,31 \pm 2,10 \mathrm{a}$ \\
Arc.1 & $82,00 \pm 15,25 \mathrm{a}$ & $68,75 \pm 13,38 \mathrm{a}$ & $82,93 \pm 2,61 \mathrm{a}$ \\
Arc.1S & $81,63 \pm 15,52 \mathrm{a}$ & $72,25 \pm 13,65 \mathrm{a}$ & $88,41 \pm 2,73 \mathrm{a}$ \\
Carioca Pitoco & $80,75 \pm 10,43 \mathrm{a}$ & $65,25 \pm 9,17 \mathrm{a}$ & $80,85 \pm 2,76 \mathrm{a}$ \\
Porrilo 70 & $73,13 \pm 9,16 \mathrm{a}$ & $57,88 \pm 7,30 \mathrm{a}$ & $78,70 \pm 4,08 \mathrm{a}$ \\
Arc.3 & $67,25 \pm 13,45 \mathrm{a}$ & $51,38 \pm 11,32 \mathrm{a}$ & $76,23 \pm 3,95 \mathrm{a}$ \\
Ipa 6 & $66,75 \pm 15,29 \mathrm{a}$ & $55,63 \pm 12,99 \mathrm{a}$ & $79,92 \pm 10,21 \mathrm{a}$ \\
Arc.3S & $65,25 \pm 12,46 \mathrm{a}$ & $58,88 \pm 11,32 \mathrm{a}$ & $88,49 \pm 1,07 \mathrm{a}$ \\
Arc.4 & $62,38 \pm 12,12 \mathrm{a}$ & $49,88 \pm 9,85 \mathrm{a}$ & $79,96 \pm 3,53 \mathrm{a}$ \\
Arc.2 & $57,00 \pm 10,35 \mathrm{a}$ & $47,38 \pm 10,05 \mathrm{a}$ & $76,09 \pm 8,13 \mathrm{a}$ \\
\hline F & $0,58^{\mathrm{ns}}$ & $0,59^{\mathrm{ns}}$ & $1,58^{\mathrm{ns}}$ \\
CV $(\%)$ & 26,65 & 28,68 & 12,63 \\
\hline
\end{tabular}

${ }^{1}$ Médias seguidas de mesma letra não diferem estatisticamente pelo teste de Tukey $(\mathrm{p} \leq 0,05)$.

${ }^{2}$ Dados originais, para análise estatística foram transformados em $(x+0,5)^{1 / 2}$. 
obtectus (Say, 1831) (Coleoptera: Bruchidae), enquanto 'Arc.1', 'Arc.3', 'Arc.4' e 'Arc.3S' apresentaram esse mesmo mecanismo em níveis inferiores. Neste trabalho o genótipo Arc.3S não alterou o período de desenvolvimento do inseto.

Os insetos adultos provenientes dos genótipos Arc.1S, Arc.1, Arc.3 e Arc.4 apresentaram peso inferior aos demais genótipos, confirmando a ocorrência de resistência nos materiais. Nos estudos realizados por Mazzoneto \& Vendramim (2002), e Wanderley et al. (1997) foi constatada redução do peso de machos e de fêmas de Z. subfasciatus provenientes dos genótipos portadores de variantes da arcelina.

Analisando-se o peso de grãos consumidos pelos carunchos (Figura 2) nota-se que os genótipos Arc.2 e Arc.3S apresentaram as menores médias de consumo, indicando a ocorrência de não-preferência para alimentação. Lara (1997) observou menor consumo de $Z$. subfasciatus nos genótipos Arc.1S e Arc.5S, seguidos por Arc.1 e Arc.2.

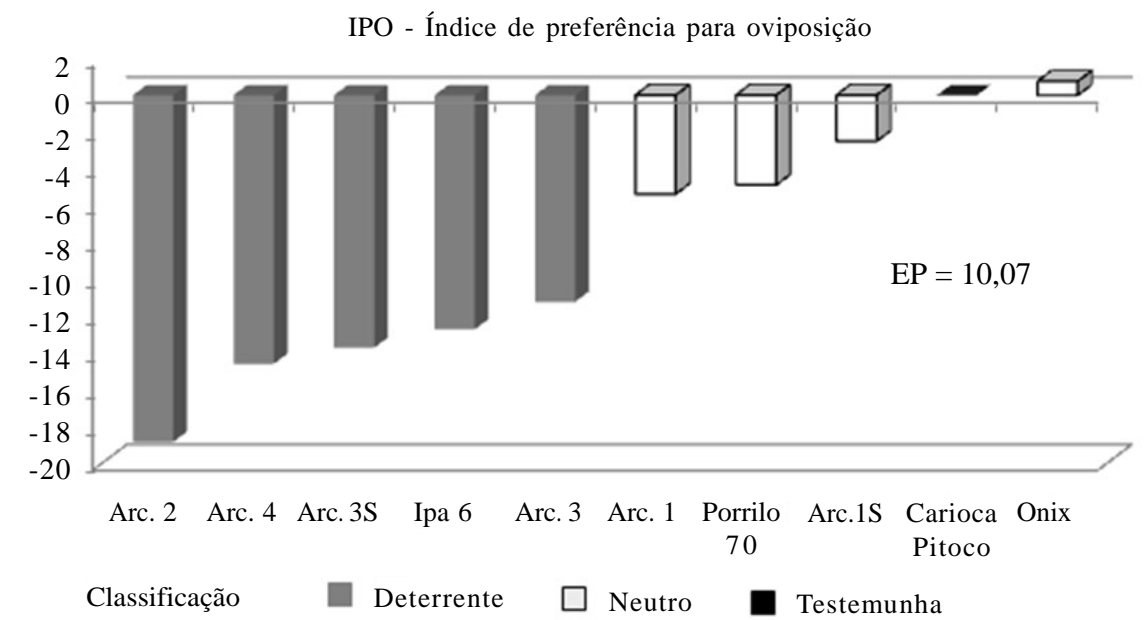

Figura 1 - Índice de preferência para oviposição e classificação dos genótipos quanto à oviposição de Z. subfasciatus.

Tabela 2 - Médias ( \pm EP) de viabilidade larval, emergência de adultos, período de desenvolvimento (ovo-adulto) e peso seco de adultos de $Z$. subfasciatus em genótipos de feijoeiro. ( $T=26 \pm 2^{\circ} \mathrm{C}$; UR $=70 \pm 10 \%$ e fotofase de $12 \mathrm{~h}$ ).

\begin{tabular}{lcccc}
\hline \multicolumn{1}{c}{ Genótipo } & $\begin{array}{c}\text { Viabilidade } \\
(\%)^{1}\end{array}$ & $\begin{array}{c}\mathrm{N}^{\circ} \text {. de insetos } \\
\text { emergidos }^{1,2}\end{array}$ & $\begin{array}{c}\text { Período de desenvolvimento } \\
(\text { dias })^{1}\end{array}$ & $\begin{array}{c}\text { Peso de adultos } \\
(\mathrm{mg})^{1,2}\end{array}$ \\
\hline Carioca Pitoco & $88,63 \pm 2,75 \mathrm{a}$ & $58,50 \pm 9,09 \mathrm{a}$ & $42,50 \pm 0,28 \mathrm{a}$ & $1,42 \pm 0,05 \mathrm{a}$ \\
Porrilo 70 & $95,29 \pm 4,08 \mathrm{a}$ & $55,63 \pm 7,36 \mathrm{a}$ & $42,56 \pm 0,42 \mathrm{a}$ & $1,29 \pm 0,02 \mathrm{~b}$ \\
Onix & $94,32 \pm 2,10 \mathrm{a}$ & $61,50 \pm 8,65 \mathrm{a}$ & $43,16 \pm 0,23 \mathrm{a}$ & $1,36 \pm 0,04 \mathrm{a}$ \\
Ipa 6 & $77,34 \pm 10,20 \mathrm{a}$ & $49,50 \pm 13,93 \mathrm{a}$ & $43,33 \pm 0,31 \mathrm{a}$ & $1,34 \pm 0,05 \mathrm{a}$ \\
Arc.3S & $96,90 \pm 1,07 \mathrm{a}$ & $56,63 \pm 10,95 \mathrm{a}$ & $44,90 \pm 0,34 \mathrm{a}$ & $1,10 \pm 0,02 \mathrm{bc}$ \\
Arc.2 & $28,90 \pm 8,12 \mathrm{~b}$ & $8,75 \pm 1,52 \mathrm{c}$ & $51,04 \pm 0,73 \mathrm{~b}$ & $1,10 \pm 0,05 \mathrm{bc}$ \\
Arc.3 & $79,93 \pm 3,95 \mathrm{a}$ & $42,75 \pm 10,49 \mathrm{ab}$ & $51,87 \pm 0,75 \mathrm{~b}$ & $1,00 \pm 0,04 \mathrm{c}$ \\
Arc.1S & $15,30 \pm 2,73 \mathrm{~b}$ & $12,13 \pm 3,45 \mathrm{bc}$ & $52,78 \pm 1,80 \mathrm{~b}$ & $0,77 \pm 0,05 \mathrm{~d}$ \\
Arc.1 & $14,42 \pm 2,61 \mathrm{~b}$ & $11,75 \pm 3,52 \mathrm{bc}$ & $54,13 \pm 1,34 \mathrm{~b}$ & $0,93 \pm 0,07 \mathrm{~cd}$ \\
Arc.4 & $80,09 \pm 3,53 \mathrm{a}$ & $41,00 \pm 9,18 \mathrm{ab}$ & $54,25 \pm 0,70 \mathrm{~b}$ & $0,95 \pm 0,04 \mathrm{~cd}$ \\
\hline F & $46,99 * *$ & $8,12 * *$ & $37,29 * *$ & $22,69 * *$ \\
CV $(\%)$ & 20,74 & 32,68 & 4,96 & 4,03 \\
\hline
\end{tabular}

${ }^{1}$ Médias seguidas de mesma letra não diferem estatisticamente pelo teste de Tukey $(\mathrm{p} \leq 0,05)$.

${ }^{2}$ Dados originais, para análise estatística foram transformados em $(x+0,5)^{1 / 2}$. 


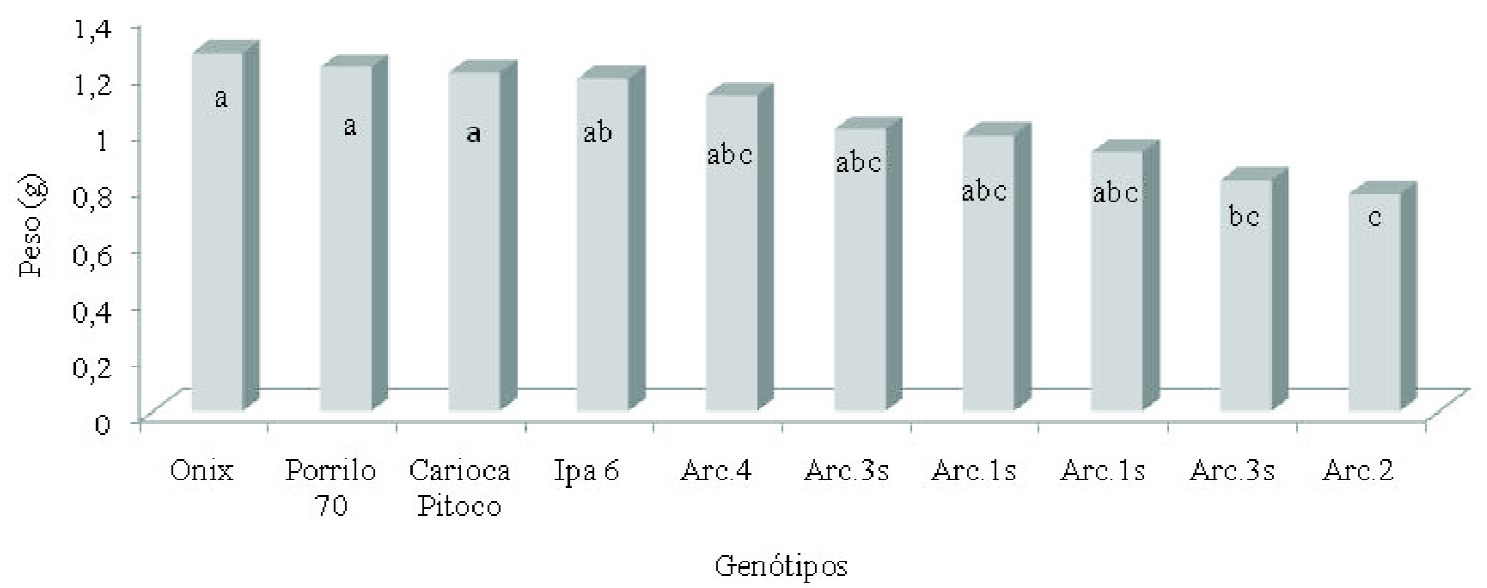

Figura 2 - Peso (g) consumido por Z. subfasciatus em diferentes genótipos de feijoeiro. Médias seguidas de mesma letra não diferem estatisticamente pelo teste de Tukey $(\mathrm{p} \leq 0,05)$.

Desta forma, observa-se que a resistência dos genótipos que contêm arcelina não está associada à nãopreferência para oviposição ou viabilidade dos ovos. No caso de 'Arc.1', a atividade tóxica da proteína arcelina sobre Z. subfasciatus está relacionada à sua ligação aos gliconjugados da superfície do trato digestivo do inseto, ocasionando danos às células epiteliais, alterando a sua estrutura e penetrando na hemocele (Paes et al., 2000).

\section{CONCLUSÕES}

'Arc.2', 'Arc.3', 'Arc.4', 'Arc.3S' e 'Ipa 6' expressam baixos níveis de não-preferência, sendo classificados como deterrentes à oviposição do inseto.

'Arc.1S' e 'Arc.1' expressam elevados níveis de antibiose; 'Arc.2', 'Arc.3' e 'Arc.4' apresentam o mesmo mecanismo, porém, em níveis inferiores.

As variantes testadas de arcelina (seja em genótipos selvagens ou melhorados) podem ser importantes fontes de resistência à $Z$. subfasciatus .

\section{REFERÊNCIAS BIBLIOGRÁFICAS}

BALDIN, E.L.L.; LARA, F.M. Efeito de temperaturas de armazenamento e de genótipos de feijoeiro sobre a resistência a Acanthoscelides obtectus (Say) (Coleoptera: Bruchidae). Neotropical Entomology, Londrina, v.33, n.3, p.365-369, may./jun. 2004.

BALDIN, E.L.L.; FRANCO, R.S.R.; SOUZA, D.R. Resistência de genótipos de feijoeiro Phaseolus vulgaris (L.) a Zabrotes subfasciatus (Boh., 1833) (Coleoptera: Bruchidae). Boletin Sanidad Vegetal Plagas, Madrid, v. 33, n. 3, p.369-375, 2007.
BALDIN, E.L.L.; LARA, F.M. Resistance of stored bean varieties to Acanthoscelides obtectus (Coleoptera: Bruchidae). Insect Science, Beijing, v.15, p.317-326, 2008.

BARBOSA, F.R.; YOKOYAMA, M.; PEREIRA, P.A.A.; ZIMMERMANN, F.J.P. Danos de Zabrotes subfasciatus (Boh.) (Coleoptera: Bruchidae) em linhagens de feijoeiro (Phaseolus vulgaris L.) contendo arcelina. Anais da Sociedade

Entomológica do Brasil, Londrina, v.29, p.113-121, mar. 2000a.

BARBOSA, F.R.; YOKOYAMA, M.; PEREIRA, P.A.A.; ZIMMERMANN, F.J.P. Estabilidade da resistência a Zabrotes subfasciatus conferida pela proteína arcelina, em feijoeiro. Pesquisa Agropecuária Brasileira, Brasília, v.35, p.895-900, mai. 2000 b.

CARDONA, C.; POSSO, C.E.; KORNEY, J.; VALOR, J.; SERRANO, M. Antibiosis effects of wild dry bean acessions on the mexican bean weevil (Coleoptera, Bruchidae). Journal of Economic Entomology, Lanham, v.82, n.1, p.310-315, 1989.

CARDONA, C.; DICK, K.; POSSO, C.E.; AMPOFO, K.; NADHY, S.M. Resistance of a common bean (Phaseolus vulgaris L.) cultivar to post-harvest infestation by Zabrotes subfasciatus (Boheman) (Coleoptera, Bruchidae). II. Storage tests. Tropical Pest Management, London, v.38, n.2, p.173-175, 1992. 
CONAB. Acompanhamento da safra brasileira: grãos safra 2008/2009, décimo primeiro levantamento, agosto/ 2008. Companhia Nacional de Abastecimento. Brasília: Conab, 2009. Disponível: <h http://Www.conab.gov.br/y. Acesso em: 04 set. 2009.

FENEMORE, P.G. Oviposition of potato tuber moth, Phthorimaea operculella Zell. (Lepidoptera: Gelechiidae); identification of host-plant factors influencing oviposition response. New Zealand Journal of Zoology, Wellington, v.7, p.435-439, 1980.

GUZMÁN-MALDONADO, S.H.; MARÍN-JARILLO, A.; CASTELLANOS, J.Z.; GONZÁLEZ DE MEJÍA, E.; ACOSTA- GALLESGOSC, J.A. Relationship between physical and chemical characteristics and susceptibility to Zabrotes subfasciatus (Boh.) (Coleoptera: Bruchidae) and Acanthoscelides obtectus (Say) in common bean (Phaseolus vulgaris L.) varieties. Journal of Stored Products Research, Oxford, v. 32, n. 1, p. 53-58, jan. 1996.

HILL, D.S. Pests of stored foodstuffs and their control. Secaucus: Kluwer Academic Publishers, 2002. 496p.

KORNEGAY, J.; CARDONA, C.; POSSO, C.E. Inheritance of resistance to Mexican bean weevil in common bean, determined by bioassay e biochemical tests. Crop Science, Madison, v.33, n.3, p.589-594. 1993.

LARA, F.M. Princípios de resistência de plantas a insetos. São Paulo: Ícone, 1991. 336p.

LARA, F.M. Resistance of wild and near isogenic bean lines with variants to Zabrotes subfasciatus (Boheman). I. Winter crop. Anais da Sociedade Entomológica do Brasil, Londrina, v.26, n.3, p. 551-560, 1997.

LARA, F.M. Resistência a Zabrotes subfasciatus (Boheman) em genótipos de feijoeiro portadores de arcelina nas sementes. III - Plantio na seca. Cultura Agronômica. Ilha Solteira, v.7, n.1, p.25-40. 1998.

MAZZONETTO, F.; BOIÇA JUNIOR, A.L. Determinação dos tipos de resistência de genótipos de feijoeiro ao ataque de Zabrotes subfasciatus (Boheman, 1833) (Coleoptera: Bruchidae). Anais da Sociedade

Entomológica do Brasil, Londrina, v.28, n.2, p.307-311, jun. 1999.
MAZZONETO, F.; VENDRAMIM, J.D. Aspectos biológicos de Zabrotes subfasciatus (Boh.) (Coleoptera: Bruchidae) em genótipos de feijoeiro com e sem arcelina. Neotropical Entomology, Londrina, v.31, n.3, p.435-439, jul./sep. 2002.

MINNEY, B.H.P.: GATEHOUSE, A.M.R.; DOBIE, P.; DENDY, J.; CARDONA, C.; GATEHOUSE, J. A. Biochemical bases of seed resistance to Zabrotes subfaciatus (Bean weevil) in Phaseolus vulgaris (common bean); a mechanism for arcelin toxicity. Journal of Insect Physiology, London, v.36, n.10, p.757-767, 1990.

ORIANI, M.A.G.; LARA, F.M.; BOIÇA JUNIOR, A.L. Resistência de genótipos de feijoeiro a Zabrotes subfasciatus (Boh.) (Coleoptera: Bruchidae). Anais da Sociedade Entomológica do Brasil, Londrina, v.25, n.2, p.213-216. 1996.

PAES, N.S.; GERHARDT, I.R.; COUTINHO, M.V.; YOKOYAMA, M.; SANTANA, E.; HARRIS, N.; CHRISPEELS, M.J.; SÁ, M.F.G. de. The effect of arcelin-1 on the structure of midgut of bruchid larvae and immunolocalization of the arcelin protein. Journal of Insect Physiology, London, v.46, n.4, p.393-402, 2000.

PEREIRA, P.A.A., YOKOYAMA, M; QUINTELA, E.D.; BLISS, F.A. Controle do caruncho Zabrotes subfasciatus (Boheman, 1833) (Coleoptera: Bruchidae) pelo uso de proteína da semente em linhagens quase isogênicas de feijoeiro. Pesquisa Agropecuária Brasileira, Brasília, v.30, n.8, p.1031-1034, ago. 1995.

POSSO, C.E.; CARDONA, C.; VALOR, J.F.; MORALES, $\mathrm{H}$. Desarrollo de lineas de frijol resistentes al gorgojo Zabrotes subfasciatus (Boheman) (Coleoptera: Bruchidae). Revista Colombiana de Entomologia. Bogotá, v.18, n.1, p.8-13. 1992.

RIBEIRO-COSTA, C. S.; PEREIRA, P.R.V.S.; LUKOVSKI, L. Desenvolvimento de Zabrotes subfasciatus (Boh.) (Coleoptera: Chrysomelidae, Bruchinae) em genótipos de Phaseolus vulgaris L. (Fabaceae) cultivados no Estado do Paraná e contendo Arcelina. Neotropical Entomology, Londrina, v.36, n.4, p.560-564. 2007.

SCHOONHOVEN, A. van; CARDONA, C. Low levels of resistance to the Mexican bean weevil in dry beans. Journal of Economic Entomology, Lanham, v.75, n.4, p.567-569. 1982. 
SCHOONHOVEN, A. van; CARDONA, C.; VALOR, J. Resistance to the bean weevil and the Mexican bean weevil (Coleoptera: Bruchidae) in noncultivated common bean accessions. Journal of Economic Entomology, Lanham, v.76, n.6, p.1255-1259. 1983.

WANDERLEY, V.S.; OLIVEIRA, J.V.; ANDRADE

JUNIOR, M.L. Resistência de cultivares e linhagens de
Phaseolus vulgaris L. a Zabrotes subfasciatus (Boh.) (Coleoptera: Bruchidae). Anais da Sociedade Entomológica do Brasil, Londrina, v.26, n.2, p.315-320, 1997.

YOKOYAMA, M. Principais pragas e seu controle. In: ARAÚJO, R.S.; RAVA, C.A.; STONE, L.F.; ZIMMERMANN, M.J.O. Cultura do feijoeiro comum no Brasil. Piracicaba: Potafós, 1996. p.771-786. 